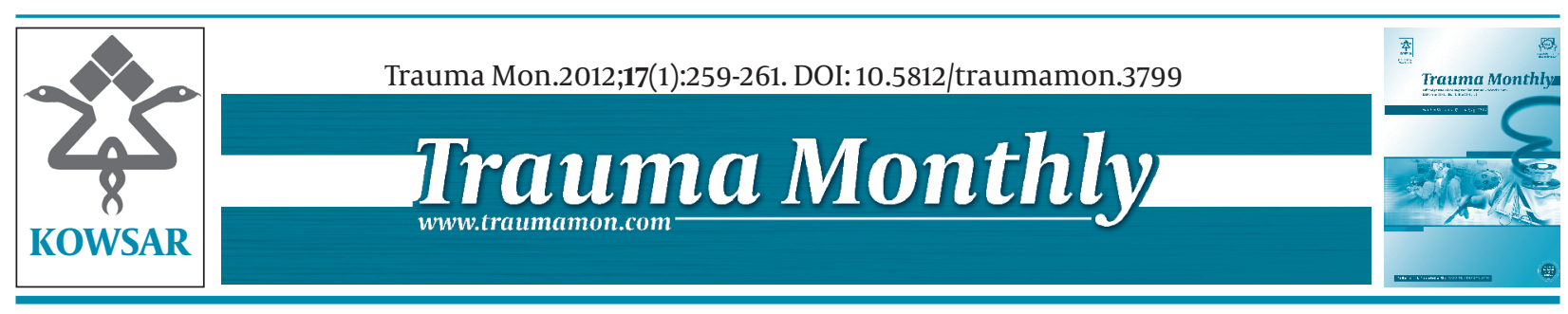

\title{
Skiing Injuries at the Dizin Ski Resort
}

\author{
Amir Hossein Khalilifar ${ }^{1^{*}}$, Mohammad Hassan Kazemi ${ }^{2}$, Arya Hamedanchi ${ }^{3}$, Mohammad \\ Javad Hosseini ${ }^{4}$ \\ ${ }^{1}$ Iran Triathlon Federation, Tehran, IR Iran \\ ${ }^{2}$ NEZAJA Preventive Medicine Department, Tehran, IR Iran \\ ${ }^{3}$ University of Social Welfare and Rehabilitation Sciences, Tehran, IR Iran \\ ${ }^{4}$ Molecular Biology Research Center, Baqiyatallah University of Medical Sciences, Tehran, IR Iran
}

\begin{tabular}{l}
\hline A R T I C L E I N F O \\
\hline Article type: \\
Short Communication \\
\hline Article history: \\
Received: 31 Jan 2012 \\
Revised: 01 Mar 2012 \\
Accepted: 10 Mar 2012 \\
\hline
\end{tabular}

Keywords:

Skiing

Wounds and Injuries

Dizin Ski Resort

\begin{abstract}
A B S T R A C T
Skiing is one of the more popular winter sports which may cause injuries. The objective of this study was to identify the most common types of injuries in Iran's largest ski resort. This cross-sectional descriptive study was performed on 1233 of patients admitted to the Dizin Resort Infirmary in 2008-2009. Obtained data included age, gender, injury type and medical interventions. All data were analyzed by SPSS 16.0 software.

Results showed that $75 \%$ of the patients were male and $25 \%$ female. The mean age was found to be 27.86 ( \pm 9.95 ) years. Most patients were between 20 -29 years old $(55.2 \%)$. The most common injury was knee trauma (14.4\%). Other common injuries were soft tissue injury (12.1\%), shoulder trauma (8.1\%), head and face trauma (7\%) and wrist trauma (5.5\%) respectively. There was a significant relationship between age and sex i.e. the age in women was less than men's $(P<0.001)$. We found a relationship between age and injury type. The lowest mean age $(24.83)$ was reported in the patients with head and face injuries and the highest mean age (44.5) was in the patients with malleolus fracture $(P<0.001)$. Additionally, sex and knee trauma proved to be connected with more prevalence in women $(P=0.001)$. There was also a significant relationship between sex and shoulder injuries showing a higher prevalence in men $(P=0.015)$.
\end{abstract}

Copyright $\odot 2012$, Kowsar Corp. All rights reserved.

Implication for health policy/practice/research/medical education:

The objective of this study was to identify the most common types of injuries in Iran's largest ski resort.

- Please cite this paper as:

Khalilifar AH, Kazemi MH, Hamedanchi A, Hosseini MJ. Skiing Injuries at the Dizin Ski Resort. Trauma Mon. 2012;17(1):259-61. DOI: 10.5812/traumamon.3799

\section{Background}

The history of skiing dates back thousands of years. The oldest ski was found in Russia, dating back 5000-6300 BC (1). Millions of people in the world go skiing every year. Physical activities are important parts of life in modern societies, and injuries inevitably occur in physical exercises and competitions (2). Skiing may cause injuries in athletes as well. Some risk factors in skiing include: High speed, hitting other skiers or obstacles, trauma caused

\footnotetext{
* Corresponding author: Amir Hossein Khalilifar, Iran Triathlon Federation, Tehran, IR Iran. Tel: +98-2188452819, Fax: +98-2177116451. Email: drkhalilifar@gmail.com

DOI:10.5812/traumamon.3799

Copyright @2012, Kowsar Corp. All rights reserved.
}

by ski equipment to the body or to others and sudden movements which cause muscular strain or tremendous pressure on the joints $(3,4)$.

The Dizin Ski Resort is the first ski resort in Iran to hold formal competitions, approved by the International Ski Federation. Dizin is located in the northern mountains of Tehran in Gajereh. The lowest part of Dizin is $2650 \mathrm{~m}$ and the highest part is $3600 \mathrm{~m}$ above sea level. The ski season in Dizin is longer than other resorts in Iran starting in November and ending in May (5).

\section{Objectives}

The objective of this study was to identify the most common injuries in the largest ski resort in Iran. Given 
that no similar study has been conducted in Iran yet, the information can help physicians as well as rescue teams to provide better services for injured skiers.

\section{Materials and Methods}

This study assessed 1223 patients during the ski season of 2008-2009. In this research, data were recorded by

Table 1. Mean age in different types of causes for referral.

\begin{tabular}{llll}
\hline Causes & Mean age & Number of patients & SD \\
\hline Medical conditions & 31.12 & 394 & 10.997 \\
Toe trauma & 25.89 & 9 & 9.943 \\
Ankle trauma & 25.26 & 43 & 5.113 \\
Shin trauma & 25.17 & 35 & 6.586 \\
Knee trauma & 26.25 & 167 & 7.992 \\
Thigh trauma & 29 & 8 & 11.032 \\
Pelvic trauma & 25.75 & 4 & 4.031 \\
Abdominal trauma & 25 & 5 & 3.464 \\
Backbone trauma & 26.41 & 17 & 8.375 \\
Chest trauma & 25.33 & 9 & 8 \\
Shoulder trauma & 26.06 & 95 & 7.537 \\
Arm Trauma & 25.62 & 13 & 9.403 \\
Elbow trauma & 26.5 & 30 & 10.281 \\
Forearm trauma & 27.58 & 12 & 9.405 \\
Wrist trauma & 24.84 & 64 & 9.585 \\
Finger trauma & 28.88 & 26 & 11.19 \\
Neck trauma & 30.09 & 11 & 8.86 \\
Head \& face trauma & 24.83 & 82 & 9.388 \\
Ankle fracture & 44.5 & 2 & 3.536 \\
Soft tissue trauma & 27.3 & 142 & 10.322 \\
Total & 27.9 & 1148 & 9.893 \\
\hline
\end{tabular}

Table 2. Causes for referral of males and females.

\begin{tabular}{lll}
\hline Type of injury & Female & Male \\
\hline Medical conditions & 74 & 320 \\
Toe trauma & 3 & 6 \\
Ankle trauma & 14 & 29 \\
Shin trauma & 10 & 24 \\
Knee trauma & 61 & 107 \\
Thigh trauma & 4 & 4 \\
Pelvic trauma & 2 & 2 \\
Abdominal trauma & 3 & 2 \\
Backbone trauma & 5 & 12 \\
Chest trauma & 1 & 8 \\
Shoulder trauma & 14 & 81 \\
Arm Trauma & 7 & 6 \\
Elbow trauma & 8 & 22 \\
Forearm trauma & 2 & 9 \\
Wrist trauma & 20 & 44 \\
Finger trauma & 6 & 20 \\
Neck trauma & 7 & 4 \\
Head \& face trauma & 23 & 59 \\
Ankle fracture & 1 & 1 \\
Soft tissue trauma & 28 & 114 \\
Total & 293 & 874 \\
\hline
\end{tabular}


paramedics or physicians at the Dizin Infirmary. All practicing physicians were orthopedic Surgeons or GPs who had passed the international course on ski medicine. Patients with unspecified complaints were excluded from the study. The data included: age, sex, chief compliant or injury types and medical interventions. All data were analyzed by SPSS16 using Kolmogrov-Smirnov, Mann-Whitney, Kruscal-Wallis, Chi-Square and Fisher Exact tests.

\section{Results}

Males comprised $75 \%$ of the cases and $25 \%$ of the cases were females. The mean age was $27.86( \pm 9.5)$. The youngest patient was 6 years-old and the oldest was 73 yearsold; $1.1 \%$ of the patients were younger than 10 years-old; $13 \%$ were between $10-19$ years old; $55.2 \%$ were 20 to 29 ; $16.7 \%$ of patients were between 30 and 39 years-old; $8.4 \%$ of patients were between 40 to 49 years-old; $5.2 \%$ of patients were between 50 to 59 years-old ; $0.2 \%$ of patients were between 60 to 69 and $0.2 \%$ of patients were above 70 years-old.

The largest group ranged between 20-29 years-old (679 patients) and the smallest groups were people between 60-69 years and above ( 2 patients). The most common chief complaint among the patients of the emergency room was their medical condition they had (33.8\%). The most frequent injury was knee trauma (14.4\%). Respectively, soft tissue injury (12.1\%), shoulder injury (8.1\%) and head and neck trauma (7\%) were the 3rd to 5 th common causes for referring to the emergency room; $33.1 \%$ of the patients received only an analgesic or anti-inflammatory drug. Bandage or splint was used for $22.7 \%$ of the patients; $9.6 \%$ of the patients received other kinds of drugs; in $9.2 \%$ of the cases no treatment was needed.

There was a significant relationship between sex and age, indicating that the mean age in females is lower than the mean age in males $(P<0.001)$. The results also indicated a relationship between age and the type of trauma $(P<0.001)$. The lowest mean age was 24.83 years which was seen in the patients with head and neck trauma and the highest mean age was 44.5 years which was seen in the patients with ankle fracture (Table 1).

Based on the results, there was a significant relationship between knee trauma and sex. Specifically knee trauma was more common in women compared to men $(P<0.001)$. Moreover, there was also a significant relationship between sex and shoulder trauma which was statistically more common in men $(P=0.015$, Table 2$)$.

\section{Discussion}

Based on the results of our study, the most common trauma was respectively: knee trauma, soft tissue trauma, shoulder trauma, head and neck trauma and wrist trauma. Longrom et al. in Scotland conducted a casecontrol study in ski season of 1999-2000 on 674 injured skiers and 336 non-injured persons; 58.9\% of injured patients were male and $41.1 \%$ were female. Unlike our findings, there was no significant relationship between sex and injury. The most common injuries were in the age group of younger than 16 years. In addition, age had a significant relationship with injury $(P=0.001) ; 12.5 \%$ of the injured had fractures, $51.7 \%$ had sprains, $9.6 \%$ had lacerations, $2.7 \%$ had joint dislocation, and $23.5 \%$ other injuries (6). Bridges et al. in eastern Colorado conducted a case series study on 1332 injured skiers. The mean age was $29.3( \pm 17.2)$. In that study, the incidence of injury in men was higher than that of women $(\mathrm{OR}=1.061)$. Additionally, the most common injury among skiers was knee trauma which matches our findings (7).

As some types of injuries occur in a specific sex or age group, safety precautions are more important for them. For example, using safety helmets can play an important role in prevention of trauma in the lower ages and safety precautions for prevention of ankle fracture in the older skiers are important. It is also recommended to use knee supports to prevent trauma in women. Having considered the frequency of injuries caused by skiing, more emphasis on the preventive methods is essential. Providing adequate training by ski instructors and an emphasis on warming up before skiing can help reduce such injuries.

\section{References}

1. Internationa Ski Federation.History of Skiing. 2012 [updated 2012; cited 12 Jan 2012]; Available from: http://history.fis-ski.com/.

2. Abernethy L, McNally O, MacAuley D, O'Neill S. Sports medicine and the accident and emergency medicine specialist. Emerg Med J. 2002;19(3):239-41.

3. Sport Medicine Information, Guide to Sport Medicine 2012 [updated 2012; cited 29 Feb , 2012]; Available from: http://www.nsmi. org.uk/articles/skiing-injuries.html\#.

4. Macnab AJ, Cadman RE, Greenlaw JV. Safety knowledge and risk behaviour of injured and uninjured young skiers and snowboarders. Paediatr Child Health. 1998;3(5):321-4.

5. I.R.Iran Ski Federation. 2012 [updated 2012; cited 29 Feb 2012]; Available from: http://www.skifed.ir.

6. Langran M, Selvaraj S. Snow sports injuries in Scotland: a casecontrol study. Br J Sports Med. 2002;36(2):135-40.

7. Bridges EJ, Rouah F, Johnston KM. Snowblading injuries in Eastern Canada. BrJ Sports Med. 2003;37(6):511-5. 